\title{
Novedades para la flora de la Región de Murcia, II
}

Pedro Solano1, Juan López-Bermúdez¹, José Moya¹, Jesús Robles², Laura Aznar², Antonio Félix Carrillo³ \& Miguel Ángel Carrión ${ }^{4}$

1. Sección de Coordinación de Agentes Medioambientales, Dirección General de Medio Ambiente, Catedrático Eugenio Úbeda Romero 3, 30071, Murcia.

2. Programa de Conservación de Flora Silvestre Protegida. Grupo Generala. Ctra. Alcantarilla km 655. 30166, Nonduermas, Murcia.

3. Latizal S. L., C/ Isaac Peral 23, bajo-b., 30151, Santo Ángel, Murcia.

4. Servicio de Biodiversidad, Caza y pesca Fluvial, Dirección General de Medio Ambiente, Catedrático Eugenio Úbeda Romero 3, 30071, Murcia.

Correspondencia

M. Á. Carrión

E-mail: mangel.carrion@carm.es

Recibido: 11 octubre 2012

Aceptado: 18 octubre 2012

Publicado on-line: 30 octubre 2012

\section{Resumen}

Se ponen en conocimiento de la comunidad científica nuevas referencias corológicas para la flora de la Región de Murcia: Cheilanthes hispanica, Dipsacus sativus, Sideritis stachydiodes.

Palabras clave: Región de Murcia, Corología, Cheilanthes, Dipsacus, Sideritis.

\begin{abstract}
New records for the flora of the Region of Murcia, II.

New records of the Murcian flora are shown to the scientific community: Cheilanthes hispanica, Dipsacus sativus and Sideritis stachydiodes.
\end{abstract}

Key words: Murcia Region, Chorology, Cheilanthes, Dipsacus, Sideritis.

\section{Introducción}

Se han localizado nuevas especies para la flora de Murcia (Sánchez-Gómez \& Guerra 2011) en el marco del Programa de Seguimiento de Flora Silvestre Amenazada de la Región de Murcia que se coordina desde el Servicio de Biodiversidad, Caza y Pesca Fluvial, adscrito a la Dirección General de Medio Ambiente, de la Consejería de Presidencia de la Región de Murcia, realizado por parte de la Brigada Móvil de Fauna y Flora del Cuerpo de Agentes Medioambientales y personal técnico del servicio, en colaboración con los agentes de las comarcas medioambientales.

\section{Cheilanthes hispanica Mett.}

España, Murcia, Mazarrón, Sierra de las Herrerías-Barranco de Montegrifo, 30SXG3860, $190 \mathrm{~m}$, 2-II-2011, Solano, (MUB-112787)
Elemento mediterráneo occidental, propio de roquedos silíceos (Muñoz-Garmendia 1986), localizado en las sierras litorales, compartiendo el hábitat con otros helechos (Anogramma leptophylla (L.) Link, Cosentinia vellea (Aiton) Tod., Polypodium cambricum L.), además de otros representantes del género Cheilanthes Swartz con los que parece desarrollar formas híbridas, algo al parecer frecuente al menos con Ch. tinaei Tod. (Salvo 1990).

Se conocen escasos ejemplares en una sola población en la que se manifiestan procesos de hibridación. Los individuos se localizan en terrenos de propiedad pública, dentro de la Red Natura 2000 y con una disponibilidad de hábitat potencial amplia, sin embargo, su estado de conservación es preocupante en el sentido de Iriondo (2004) al presentar una sola población, con escasos ejemplares y con procesos de hibridación. 
Dipsacus sativus (L.) Honck.

España, Murcia, Mazarrón, Ifre-Pastrana. 30SX G4058, 120 m, 5-III-2012. Solano, (MUB112788)

Especie de origen desconocido, de distribución holártica que ha sido cultivada desde antiguo. En la península ibérica presenta una distribución dispersa (Devesa 2007). Se ha localizado en un herbazal, en un cauce de un entorno agrícola profundamente transformado con cultivos de regadío intensivo. Probablemente se comporte en dicha localidad como una especie adventicia.

Sideritis stachydiodes Willk.

España, Murcia, Lorca, Morra del Cocón, 30SWG9180, 1250 m, 4-VII-2012. Moya, López \& Carrión, (MUB-112786)

Endemismo del sureste ibérico, cuyas principales poblaciones se ubican en la sierra de María-Maimón en la provincia de Almería (Morales 2010). Se trata de una especie rupícola, propia de roquedos calizo-dolomíticos soleados, que habita fisuras en paredones $\mathrm{y}$, en menor medida, litosuelos adyacentes.

En la bibliografía se trata como endemismo almeriense (Morales 2010), si bien con anterioridad, Pallarés (1990) hace referencia a su presencia en la vecina provincia de Granada, citando la publicación de Socorro \& Abroza (1987).

La población murciana se ubica en una sola localidad, con otras especies rupícolas como Centaurea mariana Willk., Sarcopanos enneaphylla subsp. saetabensis (Mateo \& Figuerola) O. Bolòs \& Vigo, Sedum dasyphyllum subsp. granatense (Pau) Castrov. \& Velayos. Se estima un tamaño poblacional mayor de 1000 individuos. No se ha observado en litosuelos, probablemente por la intensa carga de herbívoros de la zona.

La especie se considera Vulnerable atendiendo a los criterios de la Unión Internacional de Conservación de la Naturaleza (Moreno 2008), evaluación que tendrá que revisarse completándola con los datos murcianos. Se ubica en propiedad pública, dentro de la Red Natura 2000, con un tamaño poblacional que no parece ser en sí mismo una amenaza, y con una disponibilidad de hábitat potencial amplia, lo que infiere que presenta un estado de conservación en el sentido de Iriondo (2004) como aceptable.

\section{Agradecimientos}

A Pedro Sánchez Gómez por sus comentarios, revisar el material y facilitar su inclusión en el herbario MUB.

\section{Referencias}

Devesa JA. 2007. Dipsacus L. En Flora iberica Vol. XV (Devesa JA, Gonzalo R \& Herrero A eds.). Real Jardín Botánico. CSIC. Madrid, pp. 269-276.

Iriondo JM. (coord.) 2004. Manual de Metodología de trabajo corológico y demográfico. En Atlas y Libro Rojo de la Flora Vascular Amenazada de España (Bañares Á, Blanca G, Güemes J, Moreno JC \&. Ortiz S., eds.). Madrid. Dirección General de Conservación de la Naturaleza, pp. 17.

Morales R. 2010. Sideritis L. En Flora iberica Vol. XII (Morales R, Quintanar A \& Cabezas FJ. eds.). Real Jardín Botánico. CSIC. Madrid, pp. 234-288.

Moreno JC. (coord.) 2008. Lista Roja 2008 de la flora vascular española. Madrid. Dirección General de Medio Natural y Política Forestal. Ministerio de Medio Ambiente, y Medio Rural y Marino, y Sociedad Española de Biología de la Conservación de Plantas, pp. 48.

Muñoz-Garmendia F. 1986. Cheilanthes Sw. En Flora iberica Vol. I (Castroviejo S, Lainz M, López G, Monserrat P, Muñoz-Garmendia F, Paiva J \& Villar L, eds.). Real Jardín Botánico. CSIC. Madrid, pp. 4451.

Pallarés A. 1990. Contribución al conocimiento del G. Sideritis L. (Lamiaceae) en Almería. Instituto de Estudios Almerienses. Almería, pp. 44-46.

Sánchez-Gómez P \& Guerra J. (eds.) 2011. Nueva flora de Murcia. Plantas vasculares. Murcia. Editorial Diego Marín.

Salvo E. 1990. Guía de helechos de la Península Ibérica y Baleares. Pirámide. Madrid, pp. 188-190

Socorro O \& Aroza P. 1987. Contribución al conocimiento de la flora de Granada. Nota III. Studia botanica 6: 125. 